\title{
Negociações na formação inicial de professores de física em perspectiva Habermasiana e Freiriana: algumas implicações
}

\author{
Negotiations in pre-service physics teachers' education under Habermasian and \\ Freirian perspective: some implications \\ Lizete Maria Orquiza de Carvalho ${ }^{1}$ y Noemi Sutil ${ }^{2}$
}

\begin{abstract}
${ }^{1}$ Universidade Estadual Paulista "Júlio de Mesquita Filho"-UNESP - Programa de Pós-Graduação em Educação para a Ciência - Campus de Bauru; Faculdade de Engenharia - Departamento de Física e Química - Campus de Ilha Solteira. ${ }^{2}$ Universidade Estadual Paulista "Júlio de Mesquita Filho"-UNESP - Programa de Pós-Graduação em Educação para a Ciência - Campus de Bauru. lizete@dfq.feis.unesp.br ; noemisutil@hotmail.com
\end{abstract}

\section{Resumo}

Apresentamos discussões oriundas de pesquisa de Doutorado em Educação para a Ciência. A pesquisa apresenta como objetivo analisar negociações em um processo de problematização da prática educacional, em concepção de formação de professores como ação dialógica e ação comunicativa. Os dados foram coletados no contexto do curso de Licenciatura em Física da UNESPBrasil; eles são constituídos por registros escritos em "Diário de Campo", transcrições de gravações em áudio e vídeo, trabalhos escritos elaborados por alunos, e-mails e fóruns via intemet, documentos oficiais relativos ao curso de graduação. Os dados são analisados considerando a análise de conteúdo e de negociações. Destacamos algumas implicações para a formação de professores: formação de grupos, atores competentes discursivamente e instituições; desenvolvimento de racionalidade comunicativa e discurso teórico-prático.

Palavras-chave

Formação de professores de Física; Ação Dialógica; Ação Comunicativa; Negociações.

\section{Abstract}

We present some discussions from Education for Science Doctor Degree research. This research aims to analyze negotiations in an educational practice problem-posing process, in a conception of teachers' education as dialogic and communicative action. Data were gathered in the context of Physics' Teachers Education course at UNESP-Brazil; they are constituted by witten records in "Field Diary", audio and video records transcriptions, written works made by students, e-mails and internet foruns, official documents related to the referred course. Data were analyzed considering content and negotiations analysis. We highlight some implications to teachers' education: fomation of groups, discursively competent actors and institutions; developing of communicative rationality and theoretical-practical discourse.

Keywords

Physics teachers' education; Dialogic action; Communicative action; Negotiations.

\section{Introdução}

Apresentamos resultados e discussões de pesquisa de doutorado em Educação para a Ciência, a qual busca analisar processos de negociação vivenciados em um processo de problematização da prática educacional, em concepção de formação de professores como ação dialógica - Paulo Freire - e ação comunicativa - Jürgen Habermas. Esta pesquisa possui âmbito constitutivo em trabalho 
coletivo e colaborativo, entre alunos e professores, no Curso de Licenciatura em Física, da Faculdade de Engenharia - Universidade Estadual Paulista "Júlio de Mesquita Filho" - UNESP - Ilha Solteira/SP-Brasil, anos 2007-2008, envolvidos em 02 (duas) atividades formativas concebidas como fundamentais no processo de problematização da prática educacional em Física: Estágio Supervisionado e Pesquisa em ensino de Física. O Estágio Supervisionado e a pesquisa em ensino de Física são distinguidas como atividades formativas na medida em que possibilitam a passagem da percepção ingênua para uma percepção crítica da realidade. Assim, a estrutura profunda envolvendo questões opressoras pode ser visualizada, criticada e recriada, com a inserção na construção do mundo objetivo, social e subjetivo, nos processos de reprodução cultural, integração social e socialização.

Entre os principais momentos associados a esse processo de problematização da prática educacional, compreendidos na pesquisa estão: Grupos de estudos - (a) entre professores de ensino de Física e (b) envolvendo professores e alunos de graduação; as Disciplinas - Metodologia do Ensino de Física e Pesquisa em Educação Científica I, II e III; 02 (dois) Eventos em ensino de Física - (a) IV ENPEFIS (Encontro de Prática de Ensino de Física) e (b) Pré-ENPEFIS; Monografias desenvolvidas pelos alunos envolvendo pesquisa em ensino de Física.

A concepção de pesquisa é a investigação-ação educacional, de perspectiva emancipatória, em abordagem etnográfica. Os dados são constituídos por registros escritos em "Diário de Campo", transcrições de gravações em áudio e vídeo, trabalhos escritos elaborados pelos alunos de graduação, textos de e-mails e fóruns interativos via internet, documentos ofidais relativos ao aurso de graduação. Os dados são analisados com a utilização de procedimentos de análise de conteúdo e análise de negociações.

\section{Formação de professores em perspectiva habermasiana e freiriana - negociações}

As perspectivas habermasiana e freiriana possibilitam compreender a formação inicial de professores de Física como etapa de uma ampla e contínua formação de sociedade, cultura e personalidade e racionalidade comunicativa. Considerando a formação como processo bastante amplo, a formação inicial de professores não é concebida como etapa final. Entretanto, o papel da formação inicial é essencial. Na perspectiva defendida neste trabalho, a formação inicial é concebida como espaço de rupturas de concepções, no desenvolvimento de racionalidade comunicativa, com a formação de cultura, sociedade e personalidade. Tal defesa não abre mão da vivência de um processo de problematização da prática educacional, a qual pode ser associada à articulação entre mundos objetivo, social e subjetivo, em processo de codificação e descodificação.

A compreensão de um processo de problematização da prática educacional na perspectiva freiriana, habermasiana e de negociações possibilita analisar a percepção de uma atividade educacional como formativa ou burocrática. O Estágio Supervisionado pode ser concebido como momento de reflexão, questionamento e reconstrução da prática educacional ou como cumprimento de uma quantidade estipulada de horas a serem vivenciadas na escola. A pesquisa em ensino de Física pode ser compreendida como momento em que todos podem dizer a sua palavra, realmente se envolvendo na articulação entre mundo objetivo, social e subjetivo, ou como um trabalho burocrático.

\section{A perspectiva freireana}

Paulo Freire (1979) concebe formação como ação contínua e dialógica. Educação, em perspectiva freiriana, imprescinde do diálogo, em ação dialógica, coletiva e colaborativa, em respeito às diversas visões de mundo; concebe os homens como seres incondusos, em busca por sua humanização; não ignora a realidade opressora nem se afasta da luta por libertação; considera cada contexto em suas características individuais; ultrapassa a estrutura superficial da realidade e evidencia a estrutura profunda (FREIRE, 2002). "[...] Nenhuma prática educativa se dá no ar, mas 
num contexto concreto, histórico, social, cultural, econômico, político, não necessariamente idêntico a outro contexto" (FREIRE, 2002, p. 20).

A ação dialógica configura-se como ação cultural para a liberdade, oposição à cultura dominante, em momento de teorização da prática social, e da prática educativa; exige postura teórica, unidade dialética entre subjetividade e objetividade e trabalho criador e recriador (FREIRE, 2002). "Para os seres humanos, como seres da práxis, transformar o mundo, processo em que se transformam também, significa impregná-lo de sua presença ciadora, deixando nele as marcas de seu trabalho" (FREIRE, 2002, p. 81).

A perspectiva habermasiana

Jürgen Habermas (2001, 2003) concebe formação em termos de sociedade, cultura e personalidade,correspondendo aos mundos: social, objetivo e subjetivo - articuladamente. A formação se define em prática argumentativa, ação comunicativa e racionalidade comunicativa, com a proposição de pretensões de validez: retitude normativa - mundo social; verdade - mundo objetivo; veracidade - mundo subjetivo. Habermas (2003) diferencia ação e discurso. À ação corresponde o curso normal das atividades, o discurso emerge em situações conflituosas e que demandam renegociações no âmbito social, objetivo e subjetivo, com a colocação de pretensões de validez - discurso teórico-prático. Ele destaca que o acordo entre participantes da comunicação pressupõe capacidade lingüística, exige sujeitos linguística e interativamente competentes, desenvolvendo ações com intenção comunicativa, realizando atos de fala.

Ação comunicativa no sentido estrito pressupõe simetria de oportunidades de fala, em situação ideal de fala e comunidade ideal de comunicação, bem como o comprimento tácito de pretensões de validez. No discurso, por sua vez, os participantes buscam explicar tais pretensões de validez, buscando entendimento, acordo comunicativamente alcançado, por força do melhor argumento. "Entendimiento significa la obtención de um acuerdo entre los participantes en la comunicación acerca de la validez de uma emisión; acuerdo, el reconocimiento intersubjetivo de la pretensión de validez que el hablante vincula a ella" (HABERMAS, 2003, p. 171, grifos do autor).

A ação comunicativa no sentido amplo comporta também outros 03 (três) tipos de ação: teleológica - podendo ser convertida em ação estratégica-, de conformidade com as normas e dramatúrgica, correspondendo a 03 (três) mundos: objetivo, social e subjetivo respectivamente. "La acción comunicativa se basa en un proceso cooperativo de interpretación en que los participantes se refieren simultáneamente a algo en el mundo objetivo, en ele mundo social y en el mundo subjetivo aun cuando en su manifestación sólo subrayen temáticamente uno de estos tres componentes"' (HABERMAS, 2003, p. 171, grifos do autor).

Jürgen Habermas concebe sociedade em termos de mundo da vida e sistema. 0 mundo da vida é o pano de fundo que possibilita o desenvolvimento da ação comunicativa, comporta a interpretação/definição estabelecida e aproblemática das práticas comunicativas cotidianas. 0 sistema se constitui pela coordenação da ação por meios como dinheiro e poder, compreendendo Mercado e Estado, em ação teleológica e racionalidade cognitivo-instrumental, atribuindo aos seres humanos o papel de consumidores e cidadãos. Esses meios coordenadores da ação buscam minimizar as demandas por comunicação e o risco de desentendimentos. Na Modemidade, 0 sistema invade o mundo da vida retirando-lhe o aspecto comunicativo; essa invasão estabelece o dinheiro e o poder na coordenação de ações que seriam próprias do mundo da vida, reduzindo-as ao âmbito estratégico, o que causa sérios danos ao psicológico e corporal dos seres humanos.

0 mundo social: Estabelecidos e Outsiders

No tocante ao mundo social, em particular, é importante compreender a formação de sociedades discursivas. Nesse sentido, Elias e Scotson (2000) apresentam duas categorias básicas, obtidas a partir de estudo realizado em cidade do interior da Inglaterra: os estabelecidos, 
caracterizando as comunidades organizadas, e os outsiders, agrupando os indivíduos que não se enquadram nos pressupostos de tais grupos.

Os autores consideram a constituição e desenvolvimento de 03 (três) bairros vizinhos. A zona 1 comportava, entre outros, diversos moradores da zona 2; a zona 1 era considerada área de alto status e representava o sucesso financeiro de seus habitantes, com poucas excecõos. A zona 2 concentrava elementos da fundação da cidade, tinha moradores bastante antigos, famílias estruturadas e com fortes ligações com o local; concentrava grande parte dos coordenadores de associações e atividades de lazer dirigidas e mantidas pelas famílias. A zona 3 era constituída de imigrantes e de outros trabalhadores que foram instituindo residência no local devido a fatores como conflitos militares e necessidade de empregos.

Embora não houvesse diferenças substanciais entre os salários e empregos dos moradores das zonas 2 e 3, a diferença de status era bastante grande. A zona 2 possuía status associado a "moradores de bem", aspecto positivo reforçado por uma minoria com melhores condições. A zona 3 era relacionada a pessoas não cooperativas, de baixa moral e causadores de problemas, aspecto negativo também reforçado por uma minoria arruaceira e com problemas de desestruturação familiar. A interação de antigos e novos moradores separava a cidade em 02 (dois) grupos: 05 estabelecidos e os outsiders. Segundo os autores "nenhum desses grupos poderia ter-se transformado no que era independente do outro. Eles só puderam encaixar-se nos papéis de estabelecidos e outsiders por serem interdependentes" (ELIAS e SCOTSON, 2000, p. 181). Nesse caso espećfico, considerando que o fator econômico não era preponderante na diferença de status entre as zonas 2 e 3, a explicação foi situada nas configurações dos grupos, em aspectos estruturais; tormou-se proeminente o estudo da constituição dos grupos, sua história, suas origens. Na pesquisa apresentada neste trabalho, destacamos a formação de grupos de estabelecidos e outsiders devido à características de constituição desses agrupamentos.

Os mundos objetivo, subjetivo e social: negociações

No mundo objetivo, a concepção de Ciência a ser desenvolvida contraria a teoria positivista tradicional e se associa ao aspecto construtivo. No mundo subjetivo, a concepção de aprendizagem se reporta ao enfrentamento de desafios e à expressividade. No mundo social, as práticas educativas somente podem ser entendidas enquanto práticas sociais num sentido amplo.

Nesse terreno, o desenvolvimento de racionalidade comunicativa pode ser associada à existência de negociações que se afirmem como prática não manipulativa, em convivência democrática. Ventura (2001) atribui à negociação caráter conflitivo e cooperativo. 0 aspecto coletivo, interativo, de conjunto se destaca como desencadeador de negociações, associado à necessidade de construção coletiva, a partir de posições divergentes: acordo e resolução de conflitos. "As pessoas negociam para criar novos saberes e conhecimentos e lhes popularizar (VENTURA, 2001, p. 20, traduções nossas)".

Negociações podem ser associadas e desenvolvidas em um processo de problematização da prática educacional, em que os confilitos desencadeadores representam a necessidade do discurso teónico-prático, considerando a realidade vivencial, aspectos do mundo da vida e sua invasão pelo sistema. Os elementos de negociação podem ser associados, nessa abordagem, às pretensões de validez em uma situação ideal de fala: elementos epistemológicos (verdade), elementos sociológicos (retitude normativa) e elementos subjetivos (veracidade).

\section{Metodologia de pesquisa}

Na pesquisa que desenvolvemos 02 (duas) turmas diferentes foram solicitadas a trabalhar conjuntamente em diversos momentos, compreendendo disciplinas, reuniões e eventos. As 
negociações existentes no processo foram viabilizadas por diversas possibilidades de comunicação: aulas, exposições e eventos desenvolvidos na graduação; conversas informais entre colegas e professores em horários extra-classe; trabalhos escitos e seminários elaborados pelos alunos; aulas desenvolvidas e ministradas pelos alunos de graduação; grupos de estudos; e-mails e fóruns via internet reuniões entre professores e alunos das instituições escolares de ensino médio. As aulas e reuniões formais foram gravadas em áudio e/ou vídeo.

\section{Analise das negociações}

O estudo das negociações envolve a análise aprofundada de indicadores, elementos e fases. Os indicadores de negociação, segundo Ventura (2001), são compostos por interação (conflito), discurso, temporalidade e obra. Ele aponta as fases de consulta, proposição, contra-proposição, argumentação, avaliação e tentativa de condusão. Lebel (apud VENTURA, 2001) apresenta as fases de contato, acordo para discussão em conjunto, conhecimento do objeto de negociação, argumentação e decisão. Os elementos de negociação podem ser associados às pretensões de validez habermasianas: elementos sociológicos, epistemológicos e subjetivos.

\section{Indicadores de Negociação}

A análise que apresentamos parte da identificação de indicadores de negociação.

Podemos ressaltar como instâncias de comunicação as instituições escolares (de ensino médio, superior e organizacionais) e científicas (literatura disponível, principalmente em eventos e periódicos em ensino de Ciências/Física; pareceristas e avaliadores dos trabalhos desenvolvidos). Entre os principais negociadores estão: alunos, professores e outros profissionais de instituições escolares de ensino superior e médio; coordenadores de órgãos oficiais (Diretorias de Ensino, Secretaria de Educação do Estado de São Paulo, Coordenação de Ensino Superior).

O discurso pode ser visualizado nas diversas instâncias e possibilidades de comunicação, tanto oral quanto escrita. Os conflitos foram observados na construção de obras/consensos coletivos. A principal preocupação identificada se referia à formação de alunos e professores e constitui a principal obra, associada à construção da prática educacional em Física, tanto coletiva quanto individual.

Algumas outras obras secundárias podem ser enumeradas em relação (a) a propostas educacionais: proposta para o curso de Licenciatura em Física da UNESP-Iha Solteira, proposta para o Estágio Supervisionado, proposta para a pesquisa em ensino de Física na graduação, propostas dos alunos para a sua prática de regência e pesquisa em sala de aula, perfil de aluno oriundo do referido curso, eventos; (b) a conhecimentos: pesquisa em ensino de Física (conhecimento científico-educacional), aprendizagem de conhecimentos em Física e ensino de Física; (c) ao posicionamento dos envolvidos: argumentação e defesa de proposições. Tais obras se referem ao mundo social, objetivo e subjetivo, entretanto, a construção das mesmas articula os três mundos.

As fases de negociação são explicitadas, em uma primeira análise, relativas a cada uma das obras secundárias, e depois associadas à prática educacional em Física e formação de alunos e professores. Os elementos de negociação são destacados conforme obras e fases de negociação.

Dimensões e categorias de Análise

Os dados puderam ser enfocados sob 4 (quatro) diferentes pontos de vista: da formação de grupos; da relação social entre os grupos; do tipo de racionalidade subentendida; e da compreensão das atividades educativas pelos alunos. Do ponto de vista da formaça dos grupos, 
estes foram importantes na formação de atores competentes discursivamente (forma oral e escrita) e na reformulação de aspectos ligados às instituições. Cabe destacar, entretanto, problemas com português e escrita, e mesmo com a exposição de trabalhos, que se configuraram empecilhos no estabelecimento da comunicação.

Do ponto de vista da relação social entre grupos, dentre as duas turmas, uma era de alunos regulares, que estiveram juntos quase todo o período do curso de Licenciatura em Física, que já compartilhavam padrões de comportamento e valores, estabelecidos, e a outra turma era composta por alunos que não conduíram o curso juntamente com suas turmas de origem, outsiders. Durante o ano, observamos vários conflitos envolvendo as turmas. A diferença na percepção que elas tinham de si interferiu na aprendizagem, no envolvimento dos alunos durante o curso.

Do ponto de vista racionalidade, a realização constante de seminários e discussões envolvendo a prática educacional constituiu aspecto relevante do processo vivenciado, potencializando as capacidades comunicativas e expressivas. O discurso teórico-prático foi impresaindível para a formação, revisão do conceitos relacionados a formação, normas e direitos, expressividade, e construção/reconstrução desses aspectos e da prática educacional em Física, individual e coletiva.Entre os principais aspectos desencadeadores do discurso teórico-prático foram identificados: histórias de vida e aspectos culturais, tanto anteriores como durante o curso de Licenciatura em Física; perspectivas pessoais/profissionais; proposta do aurso de Licenciatura em Física; características das instituições escolares.

Do ponto de vista da compreensão das atividades educacionais, ora elas foram concebida como atividades formativas e ora como burocráticas, dependendo: da proposição de temas/questões a serem analisados e discutidos; da vivência do processo de problematização da prática educacional; e a perspectivas de formação posteriores, tanto como professores como pesquisadores. Entre os indícios de concepção da atividade educacional como formativa considerados estão: o envolvimento em argumentação, bem como o respeito pelo trabalho e opinião dos colegas; a busca por altemativas críticas e criativas; posicionamento teórico nas discussões; nível de desenvolvimento de negociações. Dessa forma, explicitam-se 3 (três) aspectos na compreensão das atividades como formativas ou burocráticas.

Situação limite: Questões colocadas em discussão que foram propostas pelos alunos, a partir de situações problemáticas vivenciadas no âmbito coletivo, na prática educacional, principalmente as relacionadas a preconceito, discriminação e outras dificuldades possibilitaram um posicionamento mais contundente em relação ao conhecimento, instituições e expressão. A compreensão de atividades como formativas, dessa forma, se associa aos temas/questões apresentados pelos alunos e sua relação com situações-limites. Em contraposição, as atividades educacionais apresentaram tendência a serem consideradas como burocráticas quando os temas/questões apresentados representavam apenas uma forma de terminar a graduação, originando-se em assuntos pouco significativos para os estudantes, embora, em algumas situações parecesse constituir uma preocupação dos grupos. Dessa forma, puderam ser observadas reduções ao mundo objetivo, social e subjetivo.

Reelaboração da própria prática educacional: Na compreensão das atividades como formativas, também se destacaram as justificativas e defesas dos alunos relacionadas à possibilidade de formação como professores e pesquisadores. Isto pode representar uma perspectiva de formação de caráter reflexivo, em que a própria prática educacional é colocada em análise. As próprias práticas educacionais foram, dessa forma, discutidas e reelaboradas, coletivamente e colaborativamente. Nessa perspectiva, também se destaca o interesse desenvolvido pela área da educação e particularmente pela pesquisa em ensino. Neste sentido, destaca-se o que Aluno A1 apresenta em sua justificativa do projeto de pesquisa: 
"[...] Espero que meu trabalho contribua para minha futura docência e para a educação de uma forma geral, principalmente para os professores do ensino fundamental e médio" (Aluno A1 - pré-projeto de pesquisa em ensino de Física - dezembro de 2007).

O acompanhamento das atividades deste aluno durante o processo compreende envolvimento nas práticas argumentativas e atividades propostas, com número mínimo de faltas e publicação do trabalho desenvolvido em evento de ensino de Física.

Argumentação e desenvolvimento de racionalidade comunicativa: A compreensão da atividade educacional como formativa esteve associada ao discurso teórico-prático, ou seja, a partir da argumentação se apresentaram possibilidades de mudança de concepção, de burocrática para formativa. A seguir, apresentam-se trechos de fórum realizado via internet, em que os alunos discutem questões relacionadas a conhecimentos, normas, valores e atitudes no decorrer do processo, demonstrando aspectos de negociação envolvendo elementos epistemológicos, sociológicos e subjetivos.

Quadro 3 - Argumentação de alunos e professores em fórum via internet - Fonte dos autores

\begin{tabular}{|c|c|}
\hline Argumentação de alunos e professores em forrum via internet & $\begin{array}{l}\text { Elementos em } \\
\text { negociação }\end{array}$ \\
\hline $\begin{array}{l}1 \text { - Pelo que posso perceber, as pessoas têm uma grande tendência em aceitar o que lhes é } \\
\text { proposto sem o mínimo de reflexâo. }\end{array}$ & $\begin{array}{l}\text { Subjetivos - } \\
\text { Mundo subjetivo }\end{array}$ \\
\hline $\begin{array}{l}\text { Por exemplo: A super valorização da análise de conteúdo como "metodologia única e soberana" } \\
\text { para a análise de dados. Vê-se a falta de criatividade(e porque não de opiniäo?) das pessoas, } \\
\text { com trabalhos padronizados: todo mundo pesquisa algo que os orientadores já pesquisaram, } \\
\text { citam os orientadores nos trabalhos, usam a mesma metodologia: mini-curso, entrevista, } \\
\text { análise de conteúdo, etc. No final os tcc's certamente terão um código para identificar o lote } \\
\text { não? [...] (Aluno A14-02 de setembro de 2008). }\end{array}$ & $\begin{array}{l}\text { Epistemológicos - } \\
\text { Mundo objetivo }\end{array}$ \\
\hline $\begin{array}{l}\text { 2- Nâo vejo que as pessoas aceitam a análise de conteúdo como "metodologia única e } \\
\text { soberana"... trata-se de monografias que estão pesquisando propostas de ensino }\end{array}$ & $\begin{array}{l}\text { Epistem } \\
\text { Mundo o }\end{array}$ \\
\hline $\begin{array}{l}\text { [...]. particularmente tenho aprendido muito com o mini-curso... entendendo melhor os aluno e } \\
\text { a escola... isso ta sendo de extrema importância... [...] (Aluno A6-03 de setembro de 2008). }\end{array}$ & $\begin{array}{l}\text { Subjetivos - } \\
\text { Mundo subjetivo }\end{array}$ \\
\hline $\begin{array}{l}7 \text { - Olha, até onde eu sej, num trabalho em grupo (TCCs, por exemplo) existem dois tipos de } \\
\text { pessoas: aqueles que interagem, discutem, ficam atento ao trabalho do próximo, TRABALHAM, } \\
\text { CUMPREM COM SUAS FUNÇÕES, enfim dão o melhor de si para que o GRUPO cresca e existem } \\
\text { aqueles que não sabem "...." nenhuma do que esta acontecendo no GRUPO [...] (A/uno A7-04 } \\
\text { de setembro de 2009). }\end{array}$ & $\begin{array}{l}\text { Sociológicos - } \\
\text { Mundo social }\end{array}$ \\
\hline $\begin{array}{l}17 \text { - [...] Mas apresento também minha provocacão: é possível discutimos idéias que } \\
\text { realmente interessam a todos sem levar pro plano pessoal? (Professor P2 - } 05 \text { de setembro de } \\
\text { 2009). }\end{array}$ & $\begin{array}{l}\text { Subjetivos - Mundo } \\
\text { subjetivo }\end{array}$ \\
\hline $\begin{array}{l}\text { 20- [...] Acredito que é possível manter um grupo sem haver discussões a nível pessoal, porém } \\
\text { antes de fazer qualquer crítica, a pessoa deve ler atentamente o que escreveu, pois é } \\
\text { responsável por suas falas e receberá as devidas respostas. }\end{array}$ & $\begin{array}{l}\text { Subjetivos - Mundo } \\
\text { subjetivo }\end{array}$ \\
\hline $\begin{array}{l}\text { Encerro, novamente, com o seguinte alerta: uma crítica pertinente deve ser feita } \\
\text { CREDIBIIDADE, que infelizmente é algo que se conquista com muito TRABALHO. [...] (A } \\
\text { A1 - } 08 \text { de setembro de 2008). }\end{array}$ & $\begin{array}{l}\text { Sociológicos - } \\
\text { Mundo social }\end{array}$ \\
\hline
\end{tabular}

\section{Implicações para a formação de professores de física}

Da nossa análise, conduímos que a formação de grupos constituiu-se em um dos aspectos mais significativos na formação de professores de Física. No nosso caso, ela permitiu estabelecer práticas comunicativas entre instâncias de comunicação, disponibilizar meios de comunicação e a conseqüente construção/reconstrução de normas e direitos, conhecimentos e aspectos de personalidade. Nesse sentido, é importante considerar a necessidade dos aspectos comunicativos e expressivos na proposição de atividades educacionais. 
Entendemos que racionalidade comunicativa se desenvolve com racionalidade comunicativa. Assim, destacamos a necessidade de ações explicitas do próprio curso de formação de professores no sentido de romper com uma concepção de racionalidade técnica e explicitamos a importância dos aspectos didáticos serem repensados nessa direção. Consideramos o discurso teórico-prático como sendo imprescindível para a formação, revisão dos conceitos relacionados à formação, normas e direitos, expressividade, e construção/reconstrução desses aspectos e da prática educacional em Física, individual e coletiva.

Por fim, ressaltamos a importância da consideração de elementos determinantes para o entendimento das atividades enquanto formativas ou burocráticas, em processo de problematização da prática educacional em Física. Nesse sentido, associamos, em primeiro lugar, a compreensão de atividades como formativas aos temas/questões apresentados pelos alunos e sua relação com situações-limites. Em contraposição, as atividades educacionais apresentaram tendência a serem consideradas como burocráticas quando os temas/questões apresentados representavam apenas uma forma de terminar a graduação, originando-se em assuntos pouco significativos para os estudantes, embora, em algumas situações parecesse constituir uma preocupação dos grupos. Dessa forma, pudemos observar reduções ao mundo objetivo, social e subjetivo. Em segundo lugar, a possibilidade de formação dos licenciandos como professores e pesquisadores representou uma perspectiva de formação de caráter reflexivo, em que a própria prática educacional é colocada em análise. E em terceiro lugar, associamos a possibilidade de desenvolvimento da argumentação à aprendizagem e ruptura de concepcões, possibilitando a rearticulação com os mundos objetivo, social e subjetivo.

\section{Bibliografia}

Elias, N.; Scotson, J. L. (2000). Os estabelecidos e os outsiders: sociologia das relações de poder a partir de uma pequena comunidade. Rio de Janeiro, Brasil: Jorge Zahar Ed.

Freire, P. (1979). Pedagogia do Oprimido. 7. ed. Rio de Janeiro, Brasil: Paz e Terra.

Habermas, J. (2001). Teońa de la acción comunicativa, I racionalidad de la acción y racionalización social. 3. ed. Madrid, España: Taurus.

HABERMAS, J. (2003). Teoría de la acción comunicativa, II: coítica de la razón funcionalista. 4. ed. Madrid, España: Taurus.

VENTURA, P. C. S. (2001). La négociation entre le concepteur, les objets et le public dans les musées techniques et les salons professionnels. Tese (Doutorado em Comunicação e Informação) - Université de Bourgogne, Dijon, França. 